\title{
RESSENYES
}

\section{Tomasi DI LAMPEDUSA}

\section{El Gattopardo}

Trad. de Pau Vidal, prefaci de Gioacchino Lanza Tomasi Barcelona: Proa, 2009

L'èxit d'Il Gattopardo, quan es va publicar l'any 1958, va propiciar que es traduís ben aviat arreu del món, i Catalunya no va trigar a afegir-se a aquesta onada de reconeixement internacional: el 1962 el Club Editor treia al carrer una traducció firmada per Llorenç Villalonga, El Guepard, que és la que, reeditada per diferents segells, ha circulat fins ara. La designació del traductor no devia ser, és clar, gens casual: ignorem de qui va ser la iniciativa, però tant als primers lectors catalans com al mateix Villalonga els van cridar l'atenció, tan bon punt van llegir la novel.la italiana, els paral.lelismes entre el príncep de Salina i don Toni, l'un i l'altre aristòcrates que assistien amb un somriure igualment desolat $\mathrm{i}$ escèptic a la ràpida transformació de llur illa ancestral. La coincidència d'aquests dos esperits a l'hora de seguir un mateix camí sense conèixe's -Bearn o la sala de les nines havia sortit precisament al Club Editor l'any 1961, però havia estat escrit molt abans - ha esdevingut, amb el temps, un lloc comú de la bibliografia crítica sobre Villalonga, ha estat objecte de diversos estudis específics i en aquell moment, en el moment de traduir Il Gattopardo, és evident que va passar per damunt de qualsevol altra consideració de caràcter més tècnic. L'autor de Bearn, en efecte, no era traductor, ni tampoc podia presentar credencials d'italianista. La sagacitat literària i la bona mà que posseïa com a escriptor van fer que se'n sortís prou bé, amb una redacció impecable que dissimulava hàbilment els defectes, tanmateix nombrosos, de la seva feina, derivats - com era previsible - de les mancances en el coneixement de la llengua i de la realitat italianes («portavoce della folla degli amici» / "portantveu de la follia dels amics»; «giunta» / «reunida»; "Aggio tanto lavoro» / «Faig molta feina»; «nelle camere degli ammalati gravi durante le estreme nottate» / "durant les supremes vetllades»; «si schermiva» / "feia una mica de broma»; "parlava in dialetto» / "parlava amb dialèctica»; "da un mese individuava un sicario in ciascun usciere del suo ufficio" / "des de feia un mes tenia un policia a cada una de les sortides del seu despatx»), però també d'un laxisme massa condescendent amb les solucions expeditives, de vegades adoptades per a esqui- 
var les dificultats lingüístiques, d'altres — simplement - per a fer més via, i sintetitzables bàsicament en la supressió de mots, sintagmes o frases sencers i en l'empobriment mitjançant fórmules més genèriques o més convencionals que les del text de partida: «Da ogni zolla emanava» / «Tot deixava transcendir»; «il sentore di alcova delle prime zagare» / «l'olor d'alcova de les primeres floracions»; «le zaffate dolciastre» / «una olor dolça»; «si slargavano i fianchi argentei dell'enorme zuppiera» / "es veia una enorme sopera de plata»; "Il fresco aveva disperso la sonnolenza di don Ciccio» / «La frescor havia deixondit don Ciccio».

Molts d'aquestes defectes —als quals caldria afegir unes quantes distraccions o errates, de l'estil d' «oleoso» / "odiós» o «decenza» / «decadència»- queden superats en la versió de Pau Vidal i, tot i així, la primera curiositat que ofereix el volum, inevitablement promocionat amb un fotograma del ball de Burt Lancaster i Claudia Cardinale a la coberta, és el fet que els editors de Proa no utilitzin els mèrits del traductor per a justificar el nou producte. Qui sap si condicionats pel prestigi de l'escriptor mallorquí, tant a la contracoberta com a la pàgina de crèdits recorden la traducció villalonguiana sense emetre'n cap judici, alhora que insisteixen en l'actualització filològica que qualifica el text que posen a l'abast dels lectors. Com és ben sabut, d'ençà del 1969 Feltrinelli publica Il Gattopardo d'acord amb una última versió manuscrita a la qual no s'atenia del tot l'edició que es va anar publicant des del 1958 fins a aquell any, en part per causa de les revisions a què l'autor havia sotmès la novel.la, en part per la intervenció d'altres mans. En dates més properes, el treball dels crítics sobre l'esmentat manuscrit encara ha donat lloc a noves correccions i, per tant, Pau Vidal ha traduït un text molt més fidedigne del que va poder fer servir Villalonga. Confirmen, d'altra banda, la voluntat de donar a aquest Gattopardo un valor afegit de natura filològica la introducció, obra del fill adoptiu i dipositari del llegat de Tomasi di Lampedusa, que fa sobretot una història de les vicissituds textuals de la novel.la, i un apèndix amb material narratiu i poètic dispers procedent d'autògrafs de l'autor (el material poètic - estranyament- només reproduiit en italià, sense traducció ni mètrica ni no mètrica a peu de pàgina).

Tot plegat, però, no ens ha de fer oblidar que som, primer de tot, davant d'una nova traducció, i, cosa no fácil de dir en la combinació italià-català, d'una bona traducció. L'original és una cursa d'obstacles, per la presència de llargs paràgrafs descriptius referents a encarcarades modes, arquitectures i decoracions d'època i per la intencionalitat no precisament clara d'un bon nombre de formulacions. Pau Vidal fa sempre una lectura correcta o —allà on costa de dir quina és la lectura correcta - versemblant. Comet descuits comptadíssims, i exhibeix un coneixement de l'italià i de la dinàmica contrastiva italià-català sòlid, amb poques escletxes (algun fals amic com "exaltar», "perpetu», «rescat» o «disgust»; el "proprio» convertit massa sovint en possessiu reforçat, «seu propi»). No ha pogut posar notes, i els realia o les parèmies els ha hagut de resoldre dins el cos del text, amb afegitons explicatius que passen del tot desapercebuts, com el que idea per a la locució 'ingoiare un rospo' quan s'adona que tot seguit el gripau imaginari serà descrit en les seves parts a mesura que el príncep vagi paint les sensacions desagradables que li produeix la conversa amb en Sedara: «il rospo era stato ingoiato» / «el plat de mal empassar, que la imatgeria popular li havia fet afigurar-se com un gripau fastigós, havia estat engolit» (p. 182). Posa en marxa una amplíssima explotació dels recursos lingüístics de la llengua d'arribada, alhora que cerca constantment una dicció natural i fluïda que defugi forçades literalitats: «In piedi, parlava in dialetto e gesticolava, pietoso burattino che 
aveva ridicolmente ragione» / "A peu dret, parlava en sicilià i no parava de gesticular, trist titella carregat, ridículament, de raó» (p. 165). Els inconvenients, si de cas, són conseqüència d'una desinhibició excessiva en la pràctica d'aquestes estratègies, per bé que els consideraríem només inequívocament criticables allà on de la manipulació en surt perjudicada o desvirtuada la sintaxi o en resulta una solució més opaca que la del text italià: «perfino la Maddalena, fra le due finestre, era sembrata una penitente anziché una bella biondona, svagata in chissà quali sogni, come la si vedeva sempre» / "la Magdalena mateixa, palplantada entre dues finestres, havia canviat l'aspecte d'atractiva rossa que tenia sempre per un aire de penitent, perduda en qui sap quins somnis» (p. 41); «La serata era stata compiutamente idillica» / "La vetllada havia sortit tal com estava idíl.licament prevista» (p. 100); «furono Pari del Regno, Grandi di Spagna, Cavalieri di Santiago, e quando salta loro il ticchio di essere cavalieri di Malta non hanno che da alzare un dito, e via Condotti sforna loro i diplomi senza fiatare, come se fossero maritozzi, almeno fino ad oggi» / «Van ser pars del regne, grans d'Espanya i cavallers de l'orde de sant Jaume, i el dia que els passarà pel barret de fer-se cavallers de l'orde de Malta només caldrà que ho diguin i a Via Condotti els redactaran els diplomes sense piular, com si fossin ensaïmades; si més no, fins avui» (p. 183). És potser la sintaxi, en efecte, l'àmbit en què de tant en tant es percep una certa negligència, observable també - per exemple - en la tria dels connectors, no sempre prou acurada: «alla fine non cercavano più, ma se ne andavano assorti nelle stanze più isolate, quelle dalle quali nessun grido avrebbe potuto giungere a nessuno; ma grida non vi sarebbero state, solo invocazioni e singulti bassi. Invece se ne stavano lì tutti e due stretti ed innocenti, a compatirsi l'un l'altro» / «al final havien deixat de buscar i deambulaven absorts cap als racons més isolats, els que farien impossible que cap crit arribés a orelles de ningú; però tampoc n'hi hauria hagut, de crits, tan sols invocacions i sanglots mig ofegats. I tanmateix s'estaven allà tots dos, abraçats $\mathrm{i}$ innocents, compadint-se l'un a l'altre» (p. 224) (per a l'invece proposaríem: «No, s'estaven allà tots dos $[\ldots]$ ). També resulta ocasionalment perniciosa, subratllarem finalment, l'observança massa estricta —és un dels mals del català actual- de determinades obsessions normatives: no sabem si per responsabilitat del traductor o dels correctors, apareix algun pronom feble l'antecedent del qual costa d'identificar, en algun moment es troba a faltar l'adjectiu possessiu i massa sovint el gerundi és substituït per una subordinada introduïda per «mentre».

$\mathrm{Si}$ amb aquests retrets no tenim ni de lluny, però, la intenció de desacreditar en bloc la sintaxi de la traducció, encara menys severs serem davant la recerca, en l'àmbit del lèxic, d'una genuïnitat o d'una expressivitat especials mitjançant solucions com "tornar a pesar figues» per a «ritrovare il proprio dormiveglia» (p. 244), «esquitx de xueta" per a "ebreuccio" (p. 251), "color de gos com fuig» per a "color di vomito" (p. 253) o "us ha ben fumut» per a «vi ha rovinato» (p. 275), solucions que entren, diríem, no sols dins la millor tradició traductora de casa nostra, sinó dins el radi d'acció de les atribucions que es pot permetre un traductor, potser portades al límit, però no pas en perjudici d'una eficàcia i d'una fidelitat de conjunt. Certament, Vidal de vegades puja el registre ("era nada», «eren arribats», «inoïts», «infreqüent», «d'aital manera», «arrufament», «reassossec») i més sovint el baixa: «Non subì rimprovero» / «S'estalvià així l'estirada d'orelles» (p. 55); «Don Fabrizio uscì seguito da Bendicò» / «Don Fabrizio sortí amb en Bendicó enganxat al cul» (p. 77); «alquanto fanfaronesco» / "amb un punt de milhomes» (p. 99); "per amor di quiete» / "per no embolicar la troca» (p. 136); «non dire 
troppe sciocchezze; non sai quel che dici» / «no diguis més ximpleries, que no saps per on l'enfiles» (p. 151). S'endevina, darrere la seva manera de fer, un gust per l'experimentació lúdica amb el llenguatge que és d'ell, i no pas -o molt menys - de Tomasi de Lampedusa, i que es desplega sobretot en els diàlegs i en l'òrbita popular i col.loquial. Massa sovint llegim "perepunyetes», "encantat de la vida» o "ni fred ni calor», $\mathrm{i}$ en aquest punt, per a preservar la dignitat de don Fabrizio, potser sí que era més adequat l'aristocràtic Villalonga, que, ben al contrari, demostra més pudor del que tocaria: «E adesso ha anche la faccia tosta di incaricare te $[. .$.$] di fare le sue indegne richies-$ te a quel farabutto, padre di quella sgualdrina!» / «I ara té el cinisme d'encomanar-te a tu [...] que facis les seves indignes peticions a aquest no-ningú, pare d'aquesta qualsevol» (Villalonga) / «I a sobre té la poca vergonya d'encarregar-te a tu [...] que duguis sa indigna petició a aquell miserable, el pare de la meuca!» (Vidal, p. 151). Les ambivalències i la subtil ironia del protagonista i del narrador absorbeixen, però, sense traumes la majoria dels desajustaments que introdueix Vidal, per a alguns dels quals, a més a més, som conscients que era difícil trobar una alternativa ("casa Salina» / "can Salina», «zione» / «onclarro»).

La nostra recriminació, per tant, no s’adreça a la traducció en si mateixa, sinó a la falta de consonància entre el tipus de traducció i la pruïja filològica dels paratexts. Sense arribar als extrems del seu homòleg mallorquí, no és estrany que Vidal suprimeixi $\mathrm{i}$ afegeixi mots plens o sintagmes, operacions que, tot i que no sempre trobem gaire justificables, acceptem dins una lògica global fortament naturalitzadora o fins i tot com un caprici o un mal menor $\mathrm{i}$ innocu que queda sobradament compensat per la genialitat amb què allà al costat $o$ allà mateix s'ha resolt un determinat problema o s'ha fet una determinada troballa: «Seduto su un banco se ne stava inerte a contemplare le devastazioni che Bendicò operava nelle aiuole; ogni tanto il cane rivolgeva a lui gli occhi innocenti come per esser lodato del lavoro compiuto: quattordici garofani spezzati, mezza siepe divelta, una canaletta ostruita» / "Assegut en un banc contemplava les destrosses que en Bendicó infligia als parterres; de tant en tant el gos li adreçava un esguard innocent, com si esperés les lloances per la feina feta: catorze clavells esvinçats, mig marge de murtra arrencat i un rec obstruït» (p. 49) (no s'hauria pogut traduir «inerte»?); "Venne richiamato Bendicò che inseguiva l'amico riempiendo la villa di urla gioiose» / «En Bendicó, que empaitant l'amic omplia la casa de canins alirets de goig, fou cridat a l'ordre» (p. 68) (calia afegir "canins»?); «i nostri beni, quei beni che sono il patrimonio dei poveri, saranno arraffati e malamente divisi fra i caporioni più impudenti» / "els nostres béns, aquests béns que en el fons són el patrimoni dels pobres, ens seran arrabassats perquè se'ls reparteixin els capitostos més desvergonyits» (p. 81) (calia afegir "en el fons»?, no es podia traduir «malamente»?). El que ens contraria és que les diferències entre l'edició italiana anterior al $1969 \mathrm{i}$ la posterior consisteixen precisament en això, en petites modificacions estilístiques que afecten la puntuació, o la tria d'un mot, o l'ordre dels mots, més rarament tot un sintagma, de manera que acaben essent menys significatives que les diferències entre text original i text traduït. En la traducció, sistemàticament, dos elements juxtaposats entre els quals Tomasi di Lampedusa posa només coma són units per una conjunció copulativa, i quan Tomasi di Lampedusa posa conjunció copulativa, en moltes ocasions és corregida per adversativa o li és afegit un "per això»: "Donnafugata con il suo palazzo barocco, meta di cocchi scarlatti, di cocchi verdini, di cocchi dorati, [...] La ricchezza [...] si era mutata in ornamento, in lusso, in piace- 
ri; [...] aveva lasciato cadere in fondo alla botte le fecce della cupidigia, delle cure, [...] questa ricchezza che aveva realizzato il proprio fine era composta solo di oli essenziali e come gli oli essenziali evaporava in fretta» / "Donnafugata i el seu palau barroc, meta de carros i carrosses de tons rogencs, verdosos i daurats, [...] la riquesa s'havia transformat en ornaments, luxe i plaers, [...] havia deixat caure al fons de la bóta el pòsit de l'avidesa i de les atencions, [...] aquella riquesa que havia complert el seu propi fi ara contenia exclusivament olis essencials, i per això, com els olis essencials, s'evaporava de seguida» (p. 70). La sintaxi paratàctica original esdevé sovint hipotàctica (moltes subordinacions causals o relatives), es duen a terme reordenacions molt pronunciades de les frases i són molts els imperfets que acaben transformats en pretèrits perfets i a l'inrevés. S'esquiven repeticions clarament volgudes per l'autor: "Compresso in un cantuccio del coupé, premuto dalla massa del Principe, piegato dalla prepotenza del Principe» / «Esclafat contra la paret per la còrpora del príncep, i encara més pel seu autoritarisme» (p. 59). I aquí i allà les estructures sintàctiques són esmenades a favor de formes més canòniques: «le avrebbe portato tre canne di seta ponzò, la prossima volta» / "la propera vegada li duria tres canes de seda carmesina» (p. 64). Massa intervencions, en definitiva: massa intervencions difícilment defensables amb arguments de retòrica contrastiva (majoritàriament les qüestions que acabem de detallar obeeixen al gust de l'autor, i no pas als usos de la seva tradició lingüística o literària) i massa intervencions, sobretot, perquè sigui lícit apel.lar a la filologia, que en aquest cas particular té en la traducció no ja — com acostuma a passar generalment - una germanastra difícil, sinó impossible.

Miquel Edo Julià

\section{Alda MERINI}

\section{Cuerpo de amor. Un encuentro con Jesús}

Traducció de Jeannette L. Clariond

Barcelona: Vaso Roto Ediciones, 2009, edició bilingüe, text acarat

Fer avinent al lector un llibre de la poeta Alda Merini (Milà 1931-2009) no resulta una tasca senzilla perquè, en el cas d'aquesta impressionant i encara prou desconeguda escriptora al nostre país, qualsevol aproximació a la seva obra, sigui quina sigui, requereix uns aclariments previs. De fet, cap obra d'Alda Merini no es pot comprendre si no atenem primer alguns dels esdeveniments que van marcar la seva turmentada existència. Potser aquest argument sigui aplicable a qualsevol poeta, però en el seu cas resulta imprescindible. Em permetrà, doncs, el lector un primer comentari general abans d'abordar específicament l'estudi del llibre que ens ocupa.
Alda Merini, al llarg dels seus setantavuit anys de vida, va haver de ser ingressada en un manicomi en nombroses ocasions a causa d'uns desordres mentals que arrossegava des dels setze anys, edat en la qual la poeta va descobrir, segons les seves paraules, «les primeres ombres de la seva ment». La bogeria, doncs, va ser per a Alda Merini una companya constant de viatge, que combinava amb èpoques de perllongada i notable lucidesa. En aquestes èpoques va escriure la major part de les seves obres mestres i va poder desenvolupar la seva estètica, tan peculiar i insospitada, a l'empara de l'amor per la vida i l'ésser humà. L'obra que d'una manera més bella i magistral retrata la 